Original Research Paper

\title{
Evaluation of Customer Behaviour Irregularities in Cameroon Electricity Network using Support Vector Machine
}

\author{
${ }^{1}$ Lekini Nkodo Claude Bernard, ${ }^{2}$ Ndzana Benoît and ${ }^{3}$ Oumarou Hamandjoda \\ ${ }^{I}$ P.H.D. Student, National Advanced School of Engineering, University of Yaounde I, Cameroon \\ ${ }^{2,3}$ Associate Professor, National Advanced School of Engineering, University of Yaounde I, Cameroon
}

Article history

Received: 09-09-2016

Revised: $15-12-2016$

Accepted: 05-01-2017

Corresponding Author: Lekini Nkodo Claude Bernard National Advanced School of Engineering, University of Yaounde I, Cameroon Email: claudelekini@gmail.com

\begin{abstract}
Non-Technical Losses (NTLs) in the Cameroonians electricity network are approximately 30 to $40 \%$ of production and are estimated at several billion CFA francs per year for National Electricity Company (ENEO); Hence the importance of finding effective solutions to fight against these losses. The purpose of this work was to develop a tool for the fraud detection for Cameroon National Electricity Company (ENEO) using support vector machines which consisted in data preprocessing base on the load profile, development of a model for classification, parameter optimization and detection of customers irregularities and prediction.
\end{abstract}

Keywords: Fraud Detection, Support Vector Machine, Load Profile, Irregularities, Prediction

\section{Introduction}

In Cameroon, the Cameroon National Electricity Company (ENEO) is the only electricity company with nearly one million subscribers. To this figure, it is now necessary to add people and groups who clandestinely connect to the low voltage network or who defraud by illegally handling the meters. The number of these clients of a different kind remains uncertain and difficult to define in an urban and peri-urban. They are characterized by anarchy and spontaneous habitat, a place of preference for wild and clandestine electrical connections. The losses are amount to several billions of CFA francs each year and represent a real technical and economic headache for ENEO distribution department. According to information gathered from the Interemployer grouping of Cameroon, (GICAM): "The demand of electric power of the companies grows of $8 \%$ each year while the supply progresses barely of $2 \%$. Since 2003, the difficulties of supplying electricity have caused losses estimated at more than 60 billion FCFA for ENEO, more than one point of the annual growth rate of the country". For this proposal, Cameroon's economic program for 2020 is to increase energy production from 1337 MW currently to $3000 \mathrm{MW}$. The objective is not only to fill the national deficit but also to export electricity. In order to absorb energy deficit, Cameroon is engaged in several projects such as:

- The Dibamba Power Developer Company, responsible for the production of electricity from a thermal power plant with a capacity of 86 Megawatts

- Construction of the reservoir dam of Lom Pangar in the Department of Lom and Djerem with a production capacity of 30 Megawatts

- Construction of Memve'ele Hydroelectric Generating Station on the Ntem in the Southern Region with a capacity of 201 Megawatts

- Construction of the Mekin Hydroelectric Dam with a production capacity of 15 Megawatts

- Construction of a gas-fired power plant in Kribi in the Ocean department, with a capacity of 216 Megawatts extensible to 300 Megawatts

- The commissioning of the emergency thermal program through the installation of thermal power stations in the cities of Bamenda, Ebolowa, Mbalmayo and Yaoundé. These plants operate with light fuel oil and have a total capacity of $100 \mathrm{MW}$, i.e., $20 \mathrm{MW}$ in Bamenda, $10 \mathrm{MW}$ in Mbalmayo, 10 MW in Ebolowa and 60 MW in Yaoundé (Ahala)

The research question of this study is, how can we improve the supply, availability and quality of electricity in Cameroon by reducing non-technical losses in the existing distribution network? And the Objective of the research to provide to the national electricity companies a reliable tool based on the use of Support Vector Machines (SVM) for the search non-technical losses in the distribution network, in order to eradicate fraud Distribution. Customer consumption patterns are extracted using data mining 
techniques. Based on the assumption that load profiles contain abnormalities when a fraud activity occurs, SVM classifies load profiles of customers for detection of fraud suspects. This research concentrates only on scenarios where abnormal changes appear in load profiles, indicating fraudulent activities due to the unavailability of a clear database at ENEO CAMREOON for the others factors contributing to NTL activities.

\section{Methodology}

\section{Support Vector Machine}

Support Vector Machines are often translated as Large Marge separator (SVM) which is a class of learning algorithms defined for discrimination, that is to say provide variable initially binary (Nagi et al., 2008a). They are based on the search for the optimal hyper plane margin, when possible, class or correctly separates the data while being far away as possible from all observations. The principle is to find a classifier, or a discrimination function, the generalization ability (quality forecast) is the largest possible (Nagi et al., 2008b). That is to say, to bring the issue of discrimination in the linear, the search for an optimal hyper plane and two ideas or tricks achieve this objective (Nagi et al., 2010a; 2010b):

- Define the hyper plane as a solution of a problem of constrained optimization, whose objective function is not expressed only by using scalar products between vectors

- A research nonlinear dividing surface is obtained by the introduction of a kernel function in the scalar product

As in any learning situation, a variable $Y$ is considered to predict but to simplify this basic introduction, we supposed it dichotomous with values $\{-1,1\}$ :

Let $X=X^{1}, \ldots, X^{p}$

Explanatory or predictor variables and $\phi(x)$ a model for $\mathrm{Y}$ function where:

$$
x=\left\{x^{1}, \ldots, x^{p}\right\} \in R^{p}
$$

Generally we can simply consider the variable $\{X\}$ with values in a set.

We notice:

$$
z=\left\{\left(x_{1}, y_{1}\right), \ldots,\left(x_{n}, y_{n}\right)\right\}
$$

A statistical sample size of $\mathrm{n}$ and law with unknown.

The objective is to build an estimation $\hat{\varphi}$ of $\varphi$ function of $X$ in $\{-1,1\}$ so that the probability $P(\phi(X) \neq$ $Y$ ) is supposed to be minimum.

The problem is like the search for a boundary decision in space $F$ with value in $X$.

Conventionally, a compromise must be found between the complexities of the border, which can also be expressed as its ability to spray a cloud of points. So the model fit capacity and widespread anticipation of the qualities of the model (Fourie and Calmeyer, 2004).

This is equivalent to solve a problem of classification or separation as follows in Fig. 1.

This case is defined by using the scalar product of $\mathrm{H}$ a hyper plane by its equation:

$$
f(x)=\langle w, x\rangle+b
$$

where, $w$ is orthogonal vector to the plane, $x$ point to predict. This is well positioned if and only if:

$y f(x) \succ 0$

A plan $(w ; b)$ is a separator if:

$y_{i} f\left(x_{i}\right) \geq 1 \quad \forall i \in\{1, \ldots ., \mathrm{n}\}$

and the distance from a point $\mathrm{x}$ to the plane $(w ; b)$ is define by:

$d(x)=\frac{|\langle w, x\rangle+b|}{\|w\|}=\frac{|f(x)|}{\|w\|}$

Search the maximum margin separator plane involved in solving the quadratic problem constrained below:

$\min _{w} \frac{1}{2}\|w\|^{2}$ avec $\forall i, y_{i}(\langle w, x\rangle+b) \geq 1$

The dual problem is achieved by introducing Lagrange multipliers $\alpha^{*}$ and the solution is provided by a point $\left(w^{*} ; b^{*} ; \alpha^{*}\right)$ of the Lagrangian:

$$
L(w, b, \alpha)=\frac{1}{2}\|w\|_{2}^{2}-\sum_{\mathrm{i}=1}^{\mathrm{n}} \alpha_{i}\left[y_{i}(\langle w, x\rangle+b)-1\right]
$$

The cancellation condition of partial derivatives of the Lagrangian allows writing:

$$
w^{*}=\sum_{i=1}^{n} \alpha_{i}^{*} y_{i} x_{i} \text { et } \sum_{i=1}^{n} \alpha_{i}^{*} y_{i}=0
$$




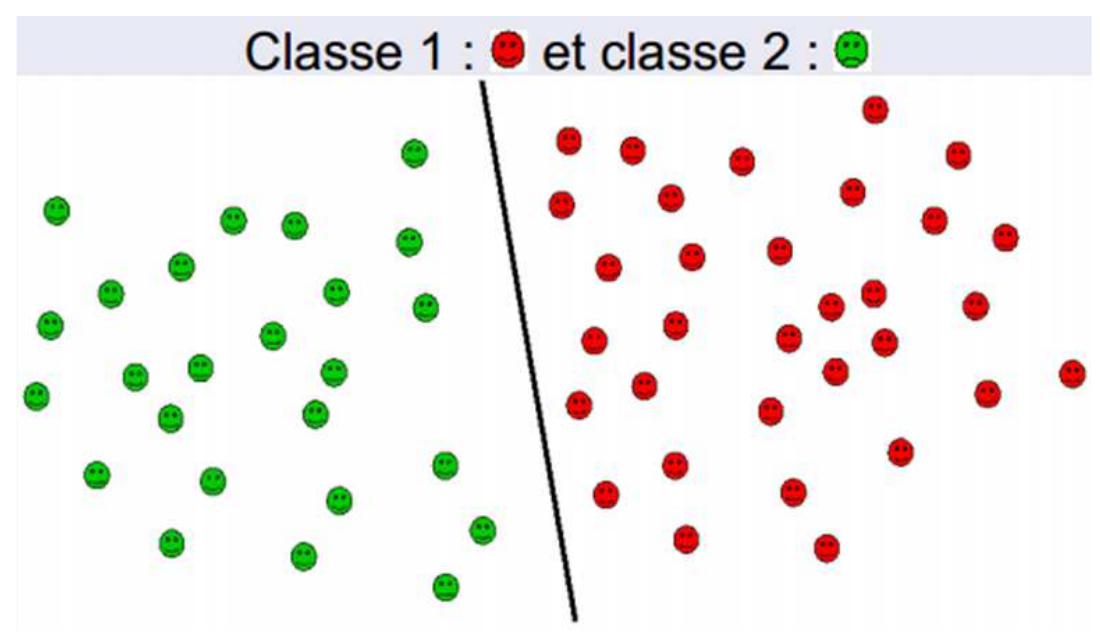

Fig. 1. Example of classification

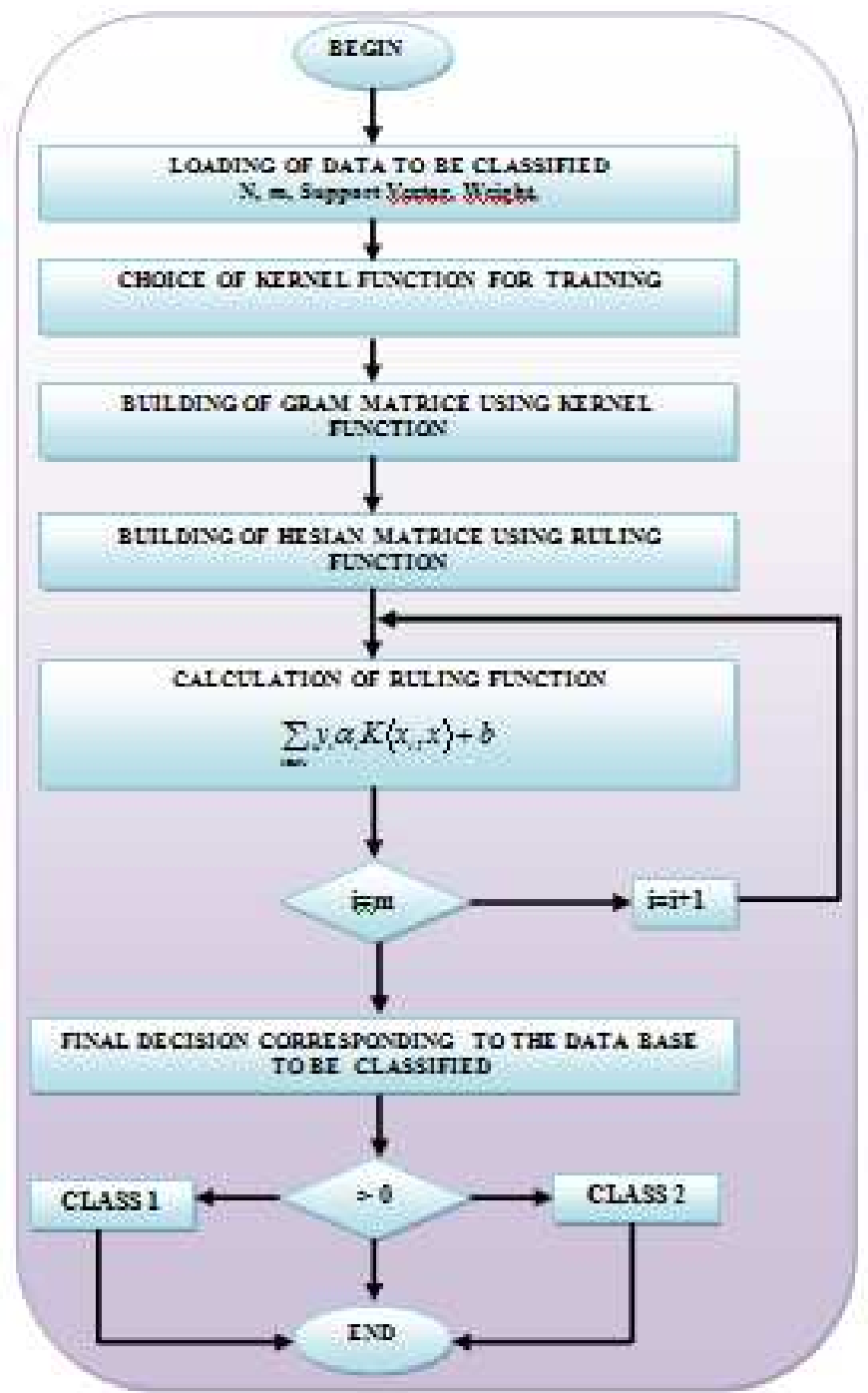

Fig. 2. Flowchart of the proposed framework for detection of NTL activities 
These equality constraints allow us to express the following dual formula:

$$
\begin{aligned}
& w(\alpha)=\sum_{i=1}^{n} \alpha_{i}-\frac{1}{2} \sum_{i, j=1}^{n} \alpha_{i} \alpha_{j} y_{i} y_{j}\left\langle x_{i}, y_{j}\right\rangle \\
& \text { avec } \sum_{i} y_{i} \alpha_{i}=0 \forall i \in\{1, \ldots ., \mathrm{n}\}, \quad 0 \leq \alpha_{i}
\end{aligned}
$$

\section{Implementation}

\section{Organization of the Method}

The research methodology framework proposed in order to develop our intelligent fraud detection system for detection, identification and prediction of NTLs activities is shown in Fig. 2.

\section{Data Acquisition}

Electricity customer consumption data was obtained from Cameroon National electricity Company (ENEO) Billing system. The data base consisted of 62000 customers for a period of 12 months (From January to December 2014) as is shown in Fig. 3 for the central region commercial unit.

But others factors contributing to NTL activities which we did not use in this work due to the unavailability of a clear database at ENEO CAMREOON such as:

- Unauthorized line tapping; tampering with meters so that meters record lower rates of consumption

- Unauthorized line diversions; stealing by bypassing meters or otherwise making illegal connections

- Inadequacies and inaccuracies of meter reading
- Inaccurate customer electricity billing

- Poor revenue collection techniques

- Arranging billing irregularities with the help of internal employees, such as making out lower bills and adjusting decimal point position on bills

- Non-payment of electricity bills

- Losses due to faulty meters and equipment

- Loss or damage of equipment/hardware that is, protective equipment, cables, conductors, switchgear etc

- Inaccurate estimation of non-metered supplies that is public lightning, agricultural consumption, rail traction etc

- In efficiency of business and technology management systems

Although some electrical power loss is inevitable, steps can be taken to ensure that it is minimized. Several measures have been applied to this end, including those based on technology and those that rely on human effort and ingenuity. Among the factors contributing to NTL activities, NTLs based on the components identified are listed in Table 1.

In the majority of factors contributing to NTL activities as indicated in Table 1, electricity customers intentionally avoid paying their bills or are involved in pilferage, theft and unauthorized use. Therefore, the intention of the present study is to focus on detecting and identifying NTL activities in the distribution network where deviations in customer behavior exist. That why, in this research, the approach is a method of data mining using support vector's machine in orders to extract patterns of customer behavior from historical consumption data base in a load profile.

Table 1. Among factors of NTLs

\begin{tabular}{lll}
\hline Components & Power utilities & Electricity customers \\
\hline Meter & $\begin{array}{l}\text { Inadequacies and inaccuracies in meter reading. } \\
\text { Losses due to faulty meters and equipment. }\end{array}$ & $\begin{array}{l}\text { Unauthorized line tapping and diversion. } \\
\text { Stealing by bypassing meters or otherwise making } \\
\text { illegal connections. } \\
\text { Tampering with meters to ensure meters record } \\
\text { lower rates of consumption. } \\
\text { Faulty meters not reported }\end{array}$ \\
$\begin{array}{l}\text { Inadequate or faulty metering. } \\
\text { Loss and damage of equipment/hardware, } \\
\text { that is, protective equipment, cables, } \\
\text { conductors, switchgear etc. } \\
\begin{array}{l}\text { Inaccurate customer electricity billing. } \\
\text { Inefficiency of business and }\end{array}\end{array}$ & $\begin{array}{l}\text { Non-payment of electricity bills. } \\
\text { Technology management system. }\end{array}$ & $\begin{array}{l}\text { Arranging billing irregularities with the help of } \\
\text { internal employees. } \\
\text { Arranging false readings by bribing meter readers. }\end{array}$ \\
$\begin{array}{l}\text { Arranging billing irregularities with the help } \\
\text { of internal employees. }\end{array}$ & $\begin{array}{l}\text { Inaccurate estimation of non-metered supplies, that } \\
\text { is, public lighting, agricultural consumption, rail } \\
\text { traction etc. }\end{array}$ \\
& $\begin{array}{l}\text { Ignoring to pay bills } \\
\text { Making out lower bills, adjusting the collection techniques. }\end{array}$ & \\
\hline
\end{tabular}




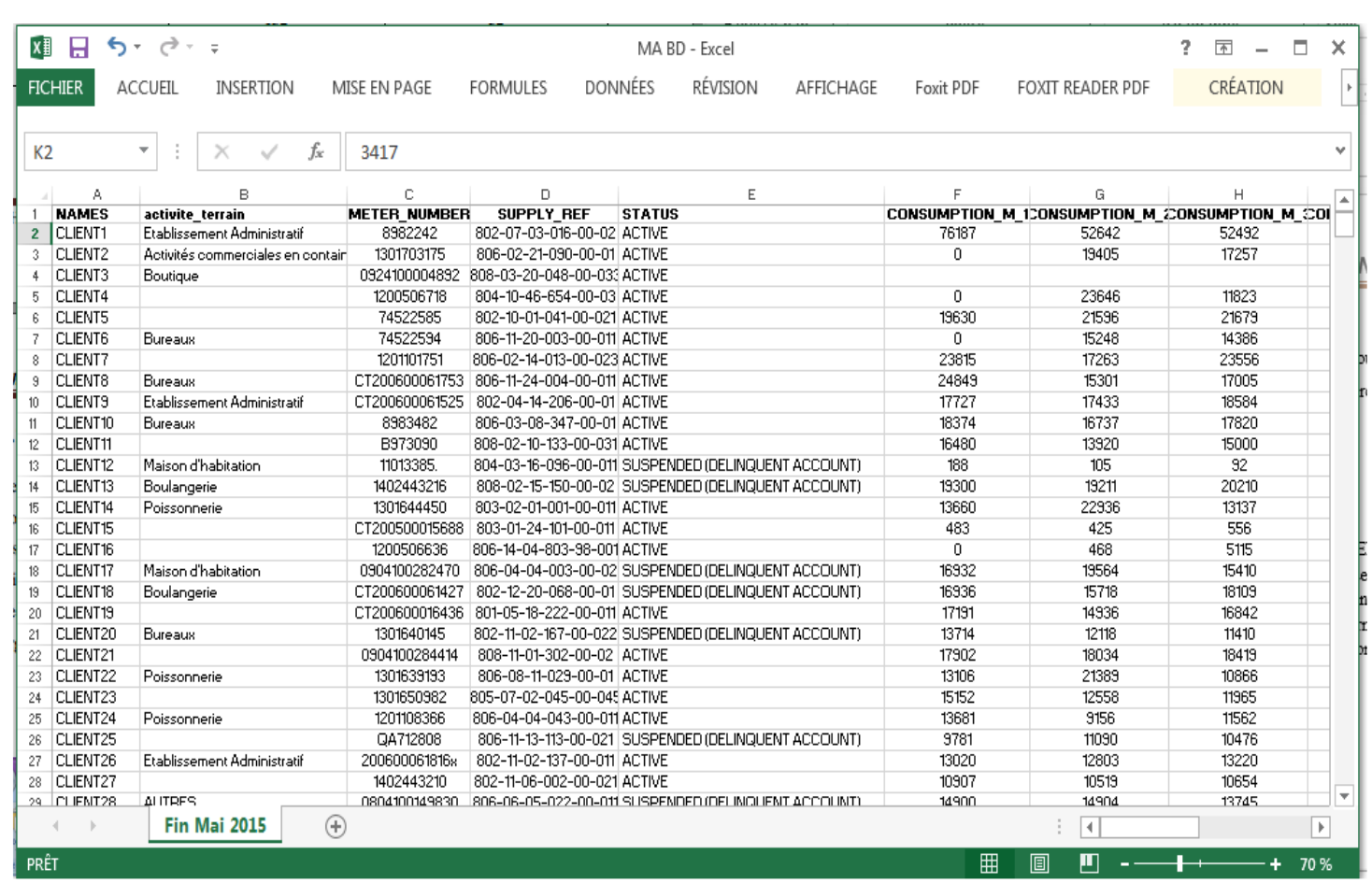

Fig. 3. Customer consumption data from ENEO

\begin{tabular}{|c|c|c|c|c|c|c|c|c|c|c|c|c|c|c|}
\hline \multirow{3}{*}{$\begin{array}{l}\text { XI } \\
\text { FICH } \\
\text { E6 }\end{array}$} & & \multirow{2}{*}{\multicolumn{2}{|c|}{$\begin{array}{l}S-c \\
\text { ACCUEIL }\end{array}$}} & \multirow{2}{*}{\multicolumn{2}{|c|}{$\overline{\overline{I N S E R T I O N}}$}} & \multirow[b]{2}{*}{ MISE EN PAGE } & \multirow{3}{*}{ FORMULES } & \multicolumn{2}{|c|}{ échantillon final - Excel } & \multirow[b]{2}{*}{ AFFICHAGE } & \multirow[b]{2}{*}{ Foxit PDF } & \multirow{2}{*}{\multicolumn{2}{|c|}{ FOXIT READER PDF }} & \multirow{2}{*}{$=$ Connexior } \\
\hline & & & & & & & & DONNÉES & RÉVISION & & & & & \\
\hline & & - & & $x$ & $f=$ & 21772 & & & & & & & & \\
\hline & & 0 & & $\mathrm{P}$ & Q & $\mathbf{R}$ & $s$ & $\mathrm{~T}$ & $u$ & $\mathrm{v}$ & w & $x$ & $\mathrm{r}$ & \\
\hline 1 & CON & NSUMP- & & ONSUMP & CONSUMP & PCONSUMP & CONSUMP & CONSUMP & CONSUMP & CONSUMP & CONSUMF & CONSUMF & CONSUMPTI & ISTATUS CLIEN \\
\hline 2 & 0,1 & 1612666 & & 0,1114284 & $4 \quad 0,111111$ & & FAUX & 0,007233 & 0,0127257 & 0,000508 & 0,007233 & 0,012726 & $\begin{array}{l}\text { FAUX } \\
\text { FAU }\end{array}$ & suspect \\
\hline 3 & & FAUX & & & 0,889307 & $\begin{array}{ll}7 & 0,9470755\end{array}$ & 0,929142 & 0,189075 & 0,5810358 & FAUX & 0,970111 & 0,839784 & 0,80159753 & normal \\
\hline 4 & & FAUX & & FAUX & , & & 0,0031409 & o & 0,0660412 & 0,009216 & 0,090714 & 0,086829 & & normal \\
\hline 5 & & $\begin{array}{l}\text { AUXX } \\
\text { FAUX }\end{array}$ & & 1 & 0,5 & $\begin{array}{ll}5 & 0,5183118\end{array}$ & 0,4621078 & 0,519961 & 0,4915842 & 0,4922608 & 0,452381 & 0,436903 & 0,41457329 & normal \\
\hline 6 & & 3293813 & & 0,9289851 & 0,941634 & 40,9558062 & 0,4021078 & 0,019961 & 0,7622676 & 0,7921365 & 0,550442 & 0,426852 & 0,68530936 & norn \\
\hline 7 & & $\begin{array}{l}\text { FAUX } \\
\text { FAUX }\end{array}$ & & 0,9289851 & $\begin{array}{l}0,941634 \\
1\end{array}$ & $\begin{array}{ll}4 & 0,9558002 \\
8 & 0,8560467\end{array}$ & 0,8390609 & .756165 & 0,720947 & 0,6341159 & 0,536464 & 0,852964 & $\begin{array}{l}0,72488195 \\
0,724853\end{array}$ & \\
\hline 8 & & 9926401 & & 0,3037535 & $5 \quad 0,965408$ & $\begin{array}{lll}8 & 0,85000401\end{array}$ & 0,5423194 & 0,3906 & 0,1073494 & 0,2135422 & 0,210914 & $0,00<904$ & 0,18399748 & \\
\hline 9 & & 9820401 & & 0,2618477 & 0,393583 & $\begin{array}{ll}8 & 0,3168922 \\
3 & 0,31\end{array}$ & $\begin{array}{r}0,0423154 \\
0\end{array}$ & 0,107228 & 0,2596057 & 0,1545419 & 0,149671 & 368 & 0,08310785 & 5 su \\
\hline 10 & & 5027069 & & 0,4458623 & $\begin{array}{l}0,393583 \\
\end{array}$ & $7 \quad 0,386891$ & 6937355 & 0,997486 & 1 & 0,6198763 & 0,043117 & 0 & 0,58758701 & \\
\hline 11 & & 7660054 & & 0,3969793 & $\begin{array}{l}8,008401 \\
3\end{array}$ & $\begin{array}{ll}8 & 0,7777277\end{array}$ & o & 0,602795 & 0,655771 & $\begin{array}{r}0,0,284716 \\
0,2846\end{array}$ & 0,04311 & 0,145 & 0,58205591 & \\
\hline 12 & & 1000054 & & 0,4764826 & $\begin{array}{l}5 \\
6\end{array}$ & 20,591002 & 0,4744376 & 0,550102 & 0,2556237 & 0,1472393 & 0 & 0,145194 & $\begin{array}{l}0,5864517 \\
0,165641\end{array}$ & \\
\hline 13 & & & & 0,1354167 & & 0,9791667 & 0,5520833 & 0,13 & 0,354 & 0,125 & 0,302083 & 0,302083 & 0,26041667 & \\
\hline $\begin{array}{l}13 \\
14\end{array}$ & & 7495872 & & 0,7250963 & & $\begin{array}{ll}1 & 0,6714364\end{array}$ & 0,5920833 & $\begin{array}{l}0,135417 \\
0,629884\end{array}$ & 0,1703357 & 0,3403963 & 0,505228 & $0,30<083$ & 0,00330215 & \\
\hline 15 & & 1570338 & & & 10,109506 & 60,3199746 & 0,1961105 & 0,241458 & 0,2191021 & 0,1424936 & 0,220465 & 0,213922 & & \\
\hline 16 & & 7286245 & & 0,5130112 & & 10,0297398 & & 0,241636 & 0,1189591 & 0,4237918 & 0,204461 & 0,19 & 0,13011152 & \\
\hline 17 & & FAUX & & 0,0846906 & $5 \quad 0,925624$ & & 0,9087948 & 0,362106 & 0,2964169 & 0,3376764 & 0,249548 & 59 & 0,39847991 & \\
\hline 18 & & 3654672 & & & 0,787671 & $\begin{array}{ll}1 & 0,8\end{array}$ & & & 0,81 & 0,8697608 & & & FAUX & \\
\hline 19 & & 9076741 & & 0,8118064 & & & & & & 15 & 0,005274 & 382 & & \\
\hline 20 & $0,4 ?$ & 4969555 & & 0,4315704 & $4 \quad 0,486836$ & $6 \quad 0,4445024$ & 0,3976746 & 0,345019 & 0,3474252 & 1 & 0,042276 & 0 & 0,00878566 & suspect \\
\hline
\end{tabular}

Fig. 4. Data normalization

\section{Customer Filtering, Selection and Extraction}

The raw data obtained from Cameroon National electricity Company (ENEO) billing system was filtered for extraction of customer load profiles and features. Hence, data mining techniques using data base querying were applied for:

- Removing repeating customers in monthly data

- Removing customers having no consumption (0 $\mathrm{kWh}$ ) throughout the entire 12 month period

- Removing customers who are not present within the entire 12 month period that is, removing new customers registered after the first month

\section{Data Normalization}

The load data needs to be represented using a normalized scale for the SVM classifier. Therefore, the monthly average $\mathrm{kWh}$ consumption feature data is normalized as follows:

$$
\text { Nindex }=\frac{x_{m}-\min \left(x_{m}\right)}{\max \left(x_{m}\right)-\min \left(x_{m}\right)}
$$

where, $x_{m}$ represents the current $\mathrm{kWh}$ consumption of the customer, $\min \left(x_{m}\right)$ and $\max \left(x_{m}\right)$ represent the minimum and maximum values in the 12 months consumption 
feature set as is shown in Fig. 4. Then typical load profiles of customers were then established, with each load profile being represented by the 12 normalized monthly average $\mathrm{kWh}$ consumption features.

\section{Feature Adjustment}

All 62000 customers were given a label, where the labels are represented by integer values; (« 1 » for suspects Customer's and «2» For normal customer's). Normalized feature values with labels are represented as a LIBSVM feature file, denoted by the matrix $\mathrm{W}$, in the form:

$$
W=\left(\begin{array}{cccccc}
1 & \cdots & 1: \operatorname{Nindex}(11) & 2: \operatorname{Nindex}(12) & \cdots & M: \operatorname{Nindex}(1 M) \\
\cdots & \cdots & \cdots & \cdots & \cdots & \cdots \\
2 & \cdots & 1: \operatorname{Nindex}(n 1) & 1: \operatorname{Nindex}(n 1) & \cdots & 1: \operatorname{Nindex}(n M) \\
\cdots & \cdots & \cdots & \cdots & \cdots & \cdots \\
2 & \cdots & 1: \operatorname{Nindex}(m 1) & 1: \operatorname{Nindex}(m 1) & \cdots & 1: \operatorname{Nindex}(n M)
\end{array}\right)
$$

where, « $m$ » Is total number of customer and « $M »$ Is the total number of months.

\section{Results and Discussion}

Results

\section{Graphics Interface}

The graphic interface of the fraud detection system here in Fig. 5, (that is, support tool to decision making in the fight against non-technical losses in the distribution network: Case of ENEO Cameroon) was developed and designed simple for the detection and identification of suspicious customers (customers list to check); the different buttons and their functionality are presented Table 2 .

\section{Data Base Selection}

To launch the software, a given excel format based file must be selected. To select a data file, users simply click on the button "Import Customer Data", it opens a file browser in the File Browser dialog box, excel file is then selected as indicated in Fig. 6. Loading of customer data base is indicated in Fig. 7.

\section{Implementation of Detection}

Once the customer data file is selected, by clicking start, the software will run in trade detection indicated in Fig. 8. It applies all the procedures mentioned in the previous listed.

Table 2. Presentation of buttons and their functionality

\begin{tabular}{ll}
\hline Botton & Function \\
\hline Browser & To choose Data Base \\
Start & To start classification \\
Unclassified & To obtain unclassified customer's list \\
Suspects list & To obtain suspects customer's list \\
Normal list & To obtain normal customer's list \\
Help & Provide help for the use of the software \\
Quit & To exit \\
\hline
\end{tabular}

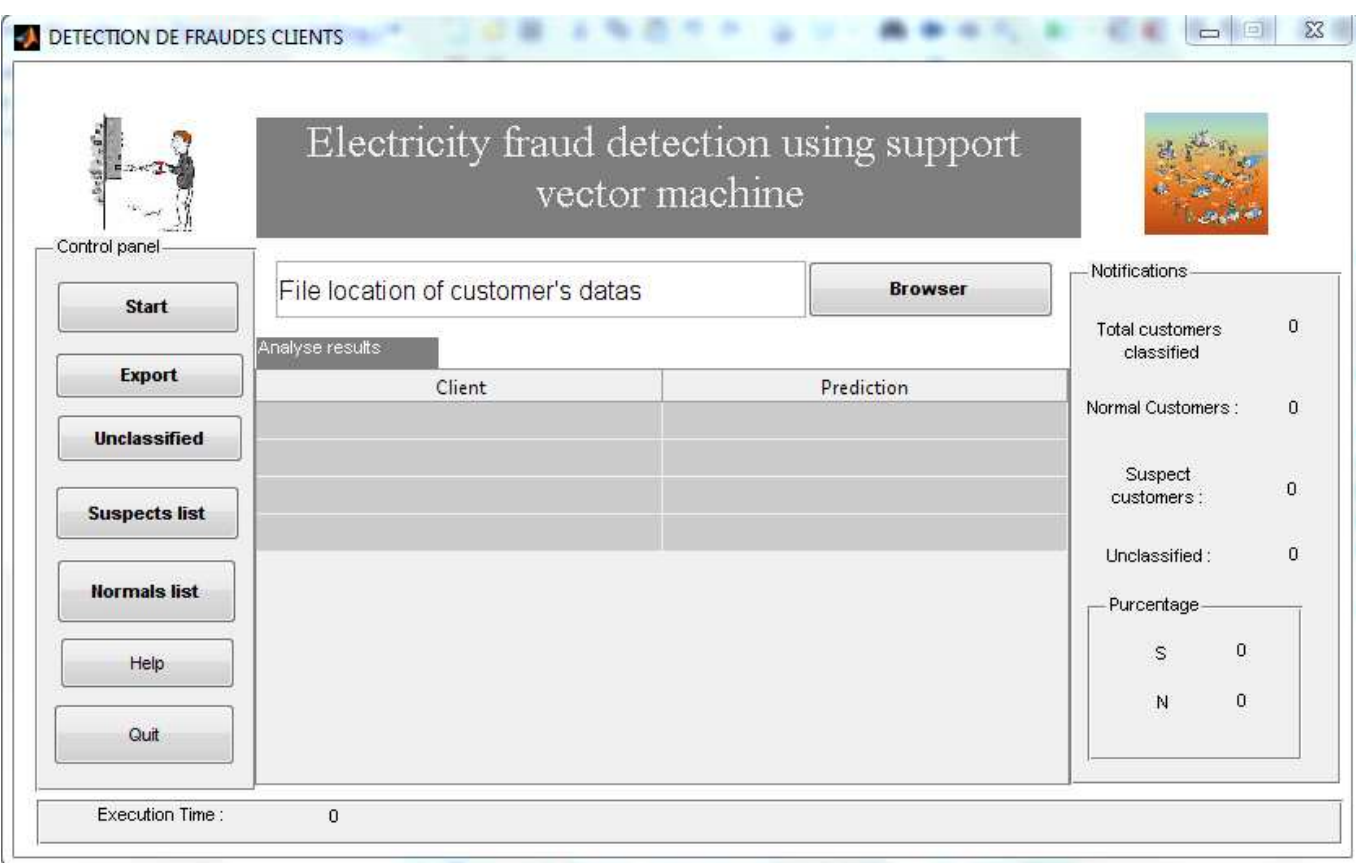

Fig. 5. Principal screen of the software 

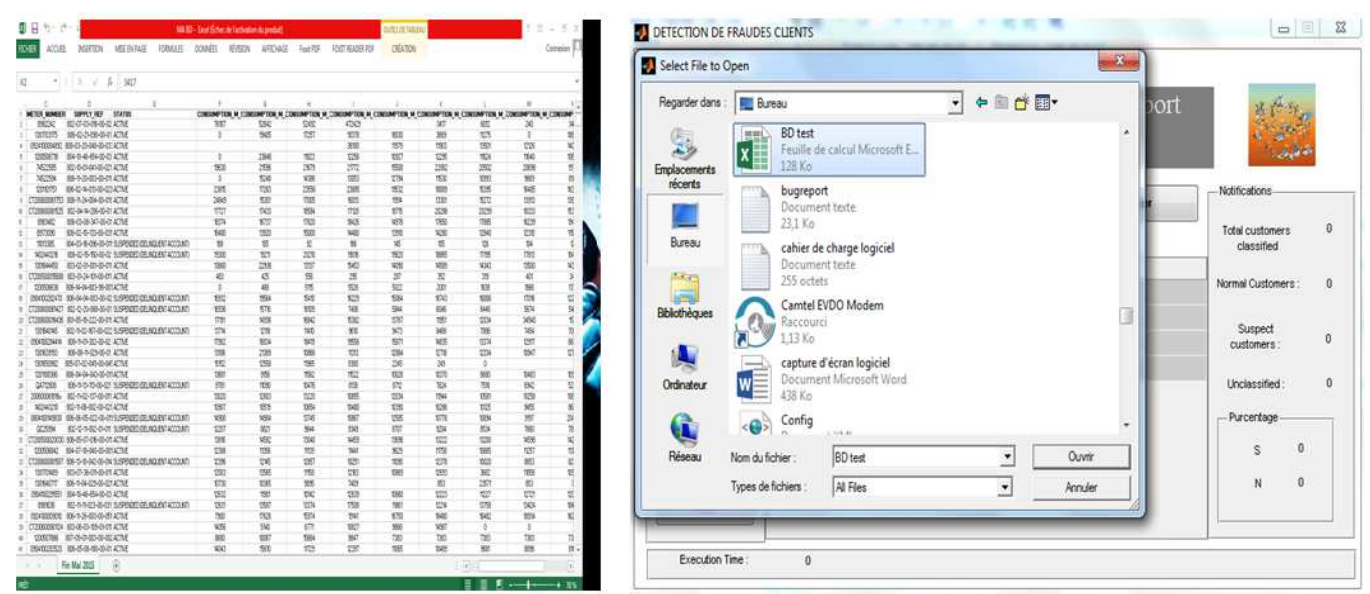

Fig. 6. Customer's data file selection

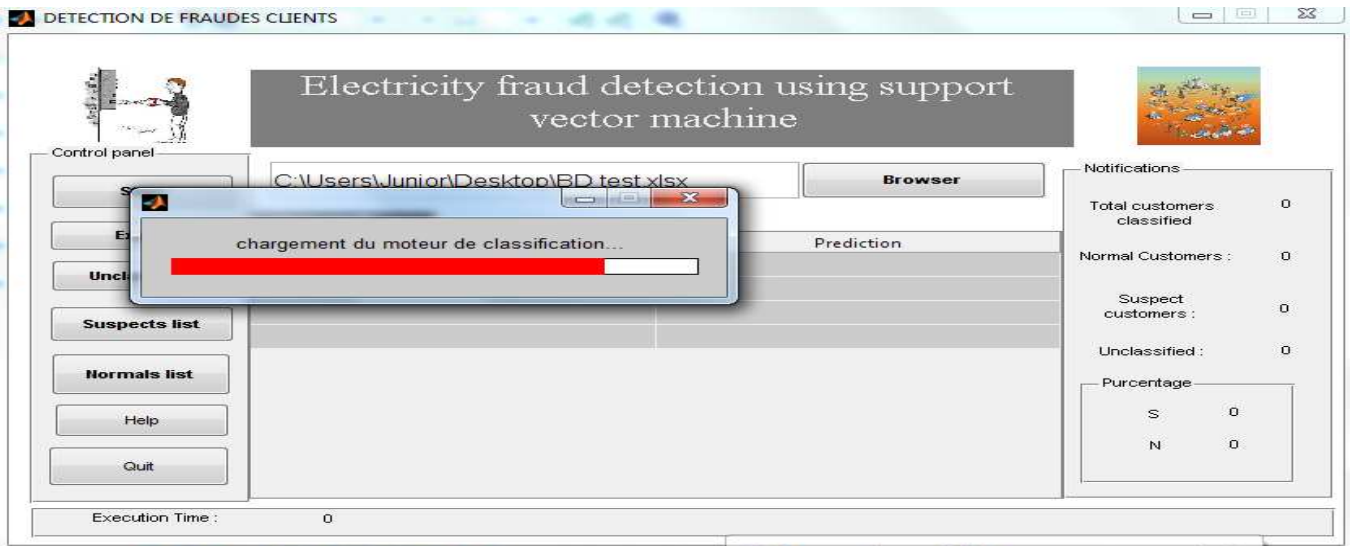

Fig. 7. Loading of customer data base

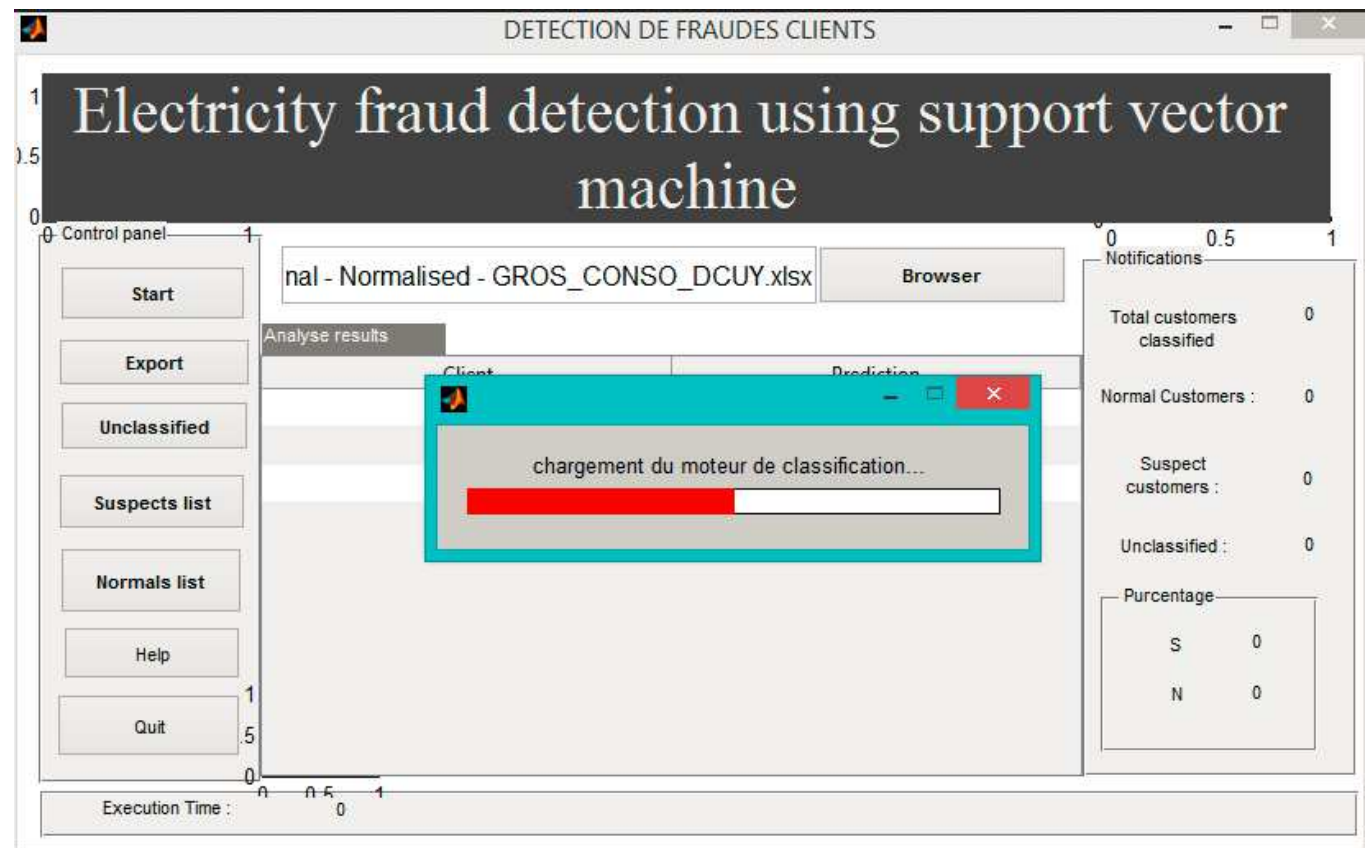

Fig. 8. Launching of the SVM classification 


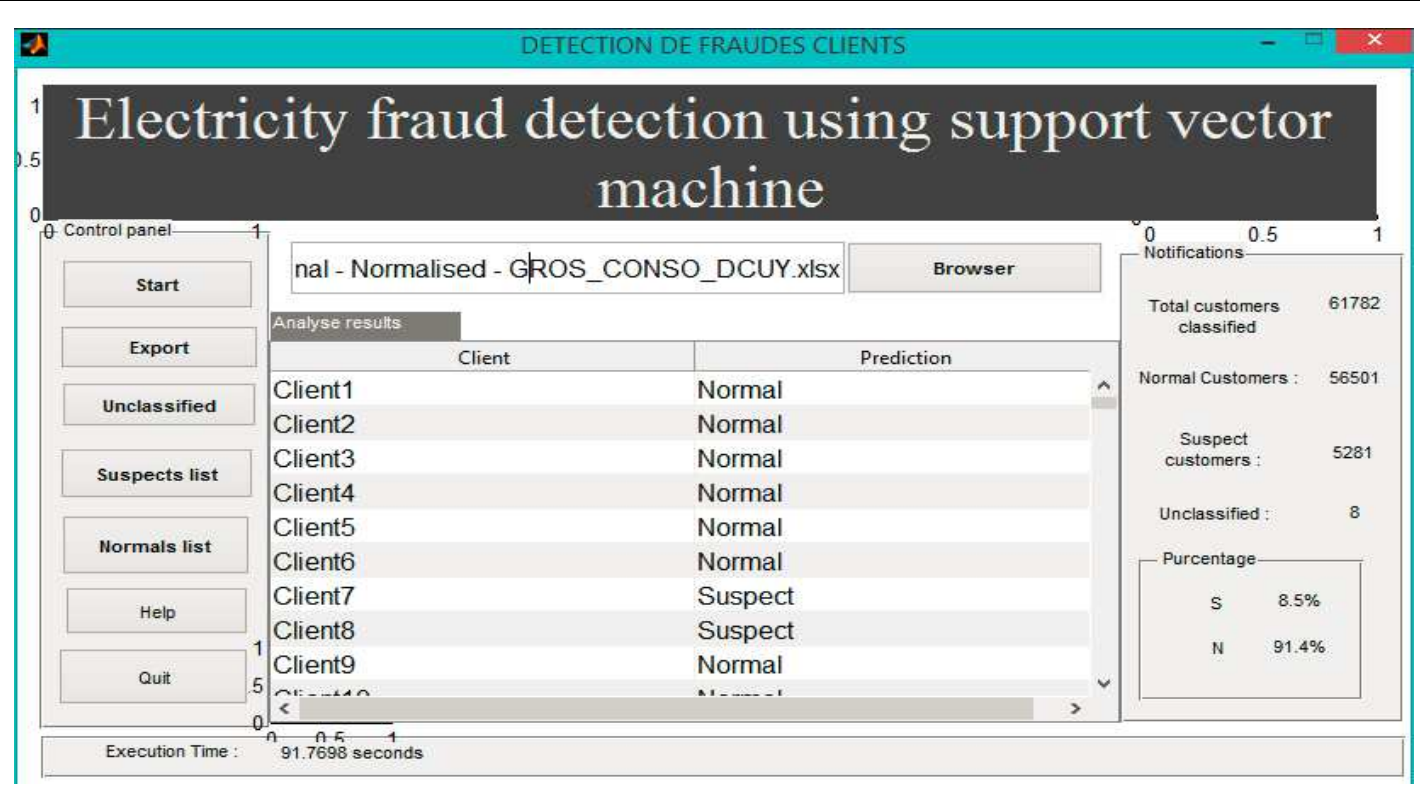

Fig. 9. Display of customers list with the prediction of their behaviors

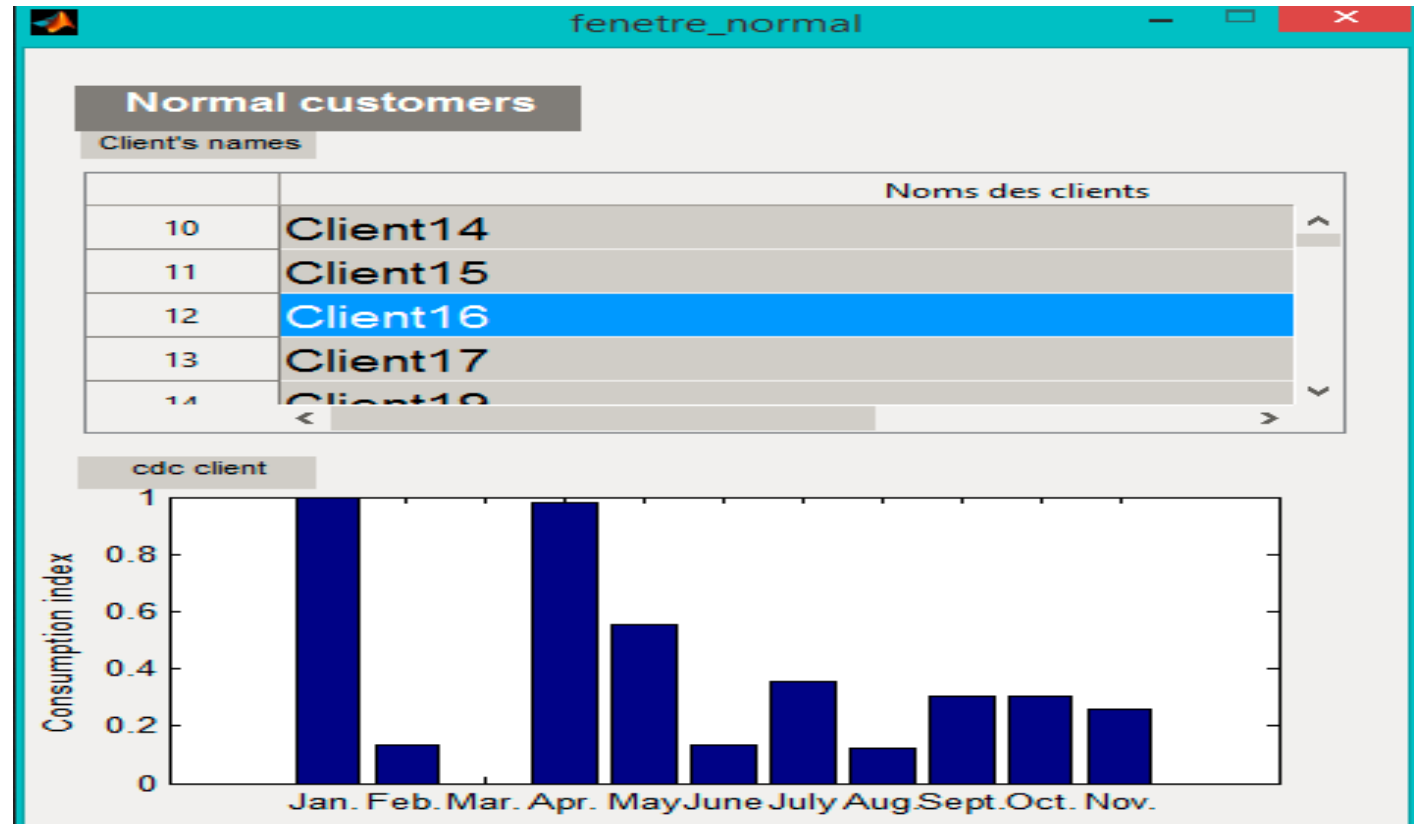

Fig. 10. Curve of suspected customers

Detection is complete once the display of trial appears in the customers list, with their status indicated in Fig. 9.

\section{Display of Customer Load Profile}

Once the software has posted the list of clients with their status, it is possible for us to visualize their load profile. Simply right click on the customer whose profile you want to see indicated in Fig. 10 to 12 respectively suspect, normal and unclassified customers.

\section{Discussion}

The training accuracy of the SVC model is estimated by tuning the SVC kernel parameter and the error penalty parameter, $C$. In this study, the RBF kernel is used, hence, the parameter gamma which controls the width of the Gaussian is to be fine-tuned.

Experimentally, by iterating different parameter combinations for our model we firstly obtained the accuracy of 75, 9\% as is shown in Fig. 13. 


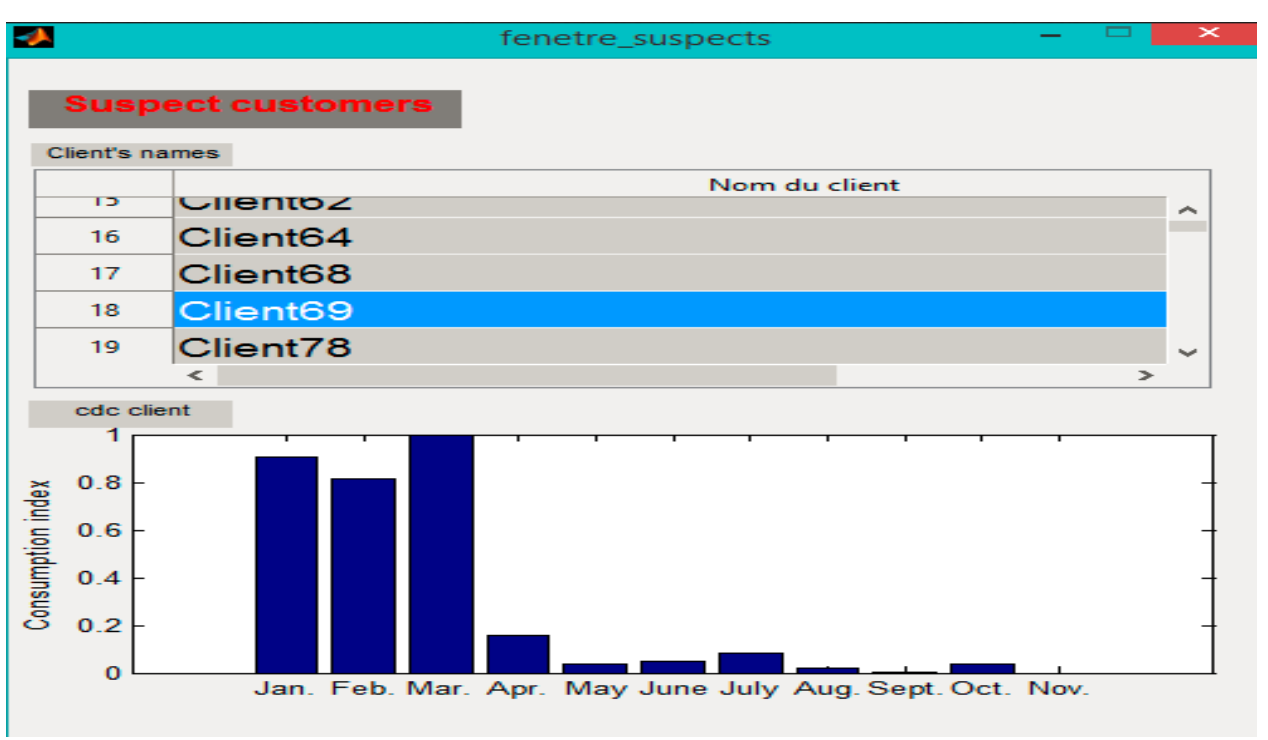

Fig. 11. Curve of normal customers

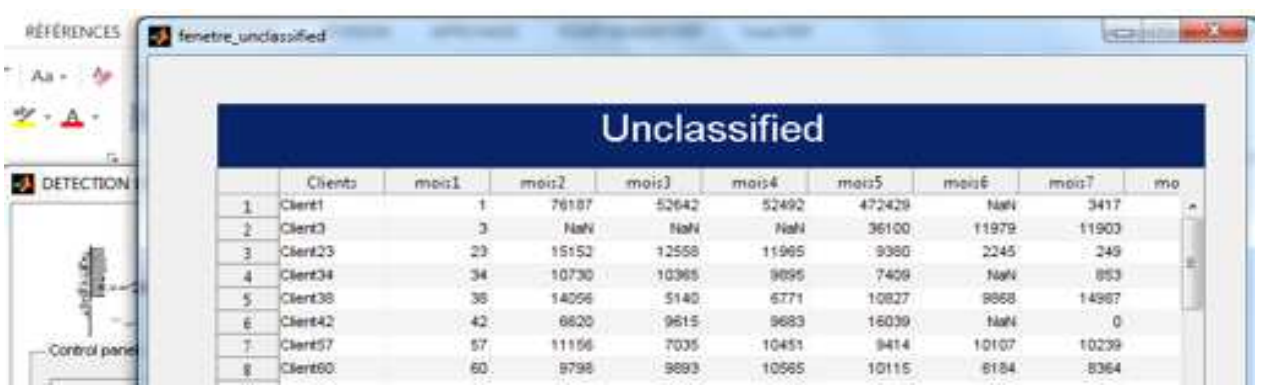

Fig. 12. Visualization of unclassified customers

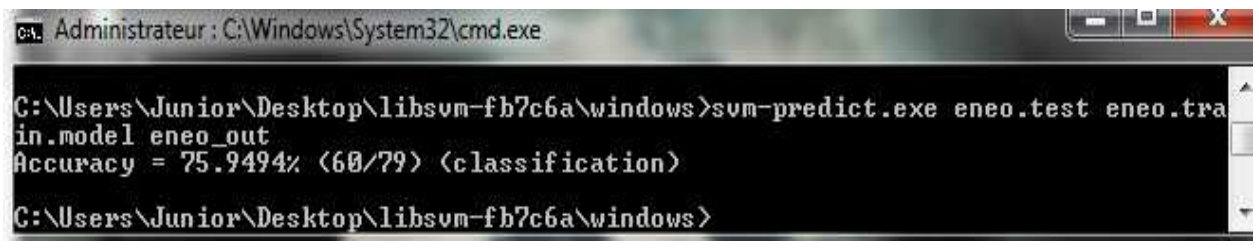

Fig. 13. LIBSVM test phase

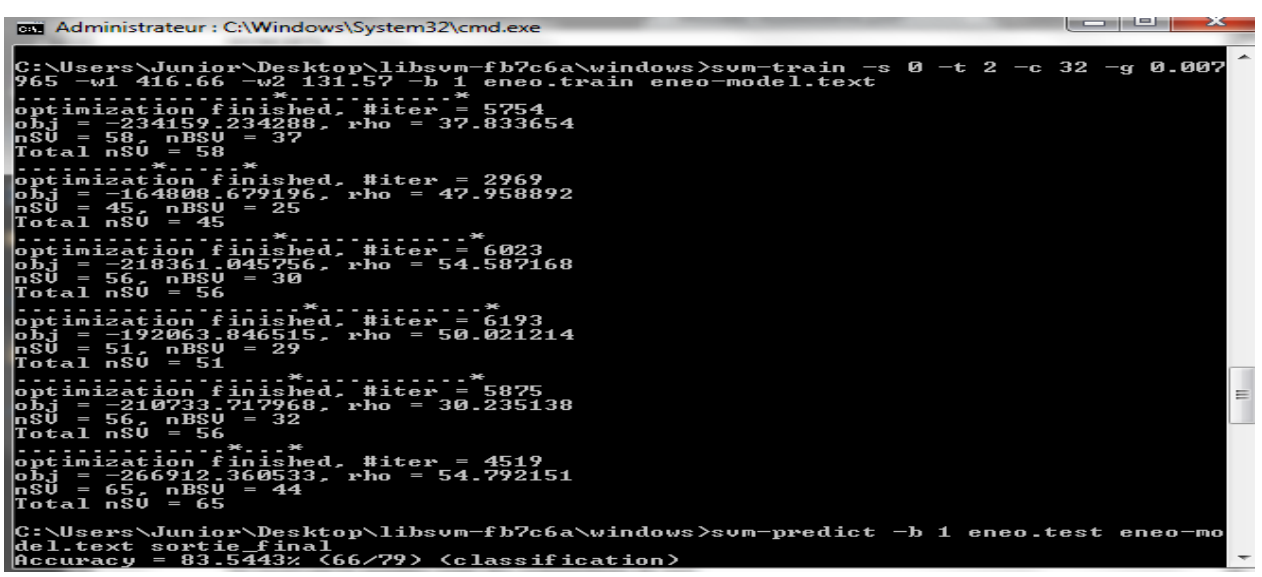

Fig. 14. Training and test after the tuning kernel parameters 
Table 3. Result of the literature

\begin{tabular}{ll}
\hline Authors & Title \\
\hline J. Nagi and Al & NTL Detection of Electricity Theft and Abnormalities for Large \\
& Power Consumers in TNB Malaysia Conference and Exposition, \\
& Seattle, Washington, United States, Mar.15-18, 2009, pp. 1-10 \\
& An Electric Energy Consumer Characterization Framework Based \\
O. Figueiredo and Al & SYSTEMS, VOL. 20, NO. 2, MAY 2005 \\
& Fraud detection in electric power distribution networks using an ANN- \\
Breno C and Al & based knowledge-discovery process, International Journal of Artificial \\
& Intelligence and Applications (IJAIA), Vol. 4, No. 6, November 2013 \\
& Detection of Abnormalities and Electricity Theft using Genetic Support \\
J. Nagi and Al & Vector Machines \\
\hline
\end{tabular}

Table 4. Data used for the construction of the model

\begin{tabular}{lll}
\hline DATA & Learning & Test \\
\hline Learning & 198 & 54 \\
Test & 59 & 20 \\
\hline
\end{tabular}

To increase this percentage of success, we use the "search grid" to optimize the kernel parameters. The best results were obtained for the optimal parameters $\mathrm{C}=8$ ET $\gamma=0.0078, w 1=416,66$; w2 $=131,57$ and we obtained the accuracy of $83 \%$ as is shown in Fig. 14

This result is in agreement with those obtained in literature as indicated in Table 3.

In order to apply a supervised learning technique, we chose a data base of 331 customers. This data base was used to establish the SVM classification model through training and testing as shown in Table 4.

We selected 61782 customers data to test our model and we obtained 56501 normal customers, 5281 suspect customers and 8 unclassified customers.

\section{Conclusion}

NTLs on the Cameroonian transmission and distribution network are about $30-40 \%$ of electricity production, causing enormous losses estimated at several billion FCFA per year to the State. Hence the importance of finding effective solutions to these losses. The purpose of this work was to develop a tool for the fraud detection for Cameroon National Electricity Company (ENEO). Firstly we present the context and the problems of our study in the introduction. Secondly, we present the methodology of support vector machines which consisted in data preprocessing, development of a model for classification, parameter optimization and testing and validation of SVM model.

For the implementation of this work we use:

- A database of nearly 62,000 customers for ENEO central region business unit

- In order to apply a supervised learning technique, we chose a data base of 331 customers and this data base was used to establish the SVM classification model through training and testing
- We selected 61782 customers in the data base to test our model

- Despite the good performance achieved, validating the proposed system required the comparison of results of the SVC protocol with practical cases detected by ENEO

The development prospects are many, including:

- Use of Genetic Algorithms for a "fine tuning" of SVM parameters such as: The penalty coefficient $\mathrm{C}$ and $\gamma$

- The fraud detection system requires the use of multiple data from different regions for learning and testing. That is to say customer data already classified: Normal or suspect

- The operation and contribution of experience ENEO agents for the development of the final decision algorithm

- To finish, we believe that fraud detection system available offline can be operated at commercial agencies ENEO to create an optimal system of customer management

- In addition, the use of the proposed system will allow ENEO improve its management of NTL and revenue protection

\section{Acknowledgement}

I am thankful to Ing DOMGUIA Jean Marie and ETOGA NDONGO who help me for the implementation of software.

\section{Author's Contributions}

All authors made substantial contributions to this paper.

Lekini Nkodo Claude Bernard: Contributed to research design, literature review, model development and manuscript preparation and revision.

Ndzana Benoît and Oumarou Hamandjoda: Contributed to conceptualization, manuscript review, revision and research supervision. 


\section{Ethics}

These authors have no ethical issues that may arise after the publication of this manuscript and confirm that this work is original and has not been published elsewhere.

\section{References}

Fourie, J.W. and J.E. Calmeyer, 2004. A statistical method to minimize electrical energy losses in a local electricity distribution network. Proceedings of the 7th IEEE AFRICON Conference, Sept. 15-17, IEEE Xplore Press, pp: 667-673.

DOI: 10.1109/AFRICON.2004.1406768

Nagi, J., K.S. Yap, S.K. Tiong and S.K. Ahmed, 2008a. Detection of abnormalities and electricity theft using genetic support vector machines. Proceedings of the IEEE Region 10th Conference, Nov. 18-21, IEEE Xplore Press, Hyderabad, India, pp: 1-6.

DOI: 10.1109/TENCON.2008.4766403
Nagi, J., K.S. Yap, S.K. Tiong, A.M. Mohammad and S.K. Ahmed, 2008b. Non-technical loss analysis for detection of electricity theft using support vector machines. Proceedings of the 2nd IEEE International Power and Energy Conference, Dec. 13, IEEE Xplore Press, Johor Bahru, Malaysia, pp: 907-912. DOI: 10.1109/PECON.2008.4762604

Nagi, J., K.S. Yap, S.K. Tiong, S.K. Ahmed and F. Nagi, 2010b. Improving SVM-based nontechnical loss detection in power utility using the fuzzy inference system. IEEE Trans. Power Delivery, 26: 1284-1285. DOI: 10.1109/TPWRD.2010.2055670

Nagi, J., K.S. Yap, S.K. Tiong, S.K. Ahmed and M. Mohamad 2010a. Nontechnical loss detection for metered customers in power utility using support vector machines. IEEE Trans. Power Delivery, 25: 1162-1171. DOI: 10.1109/TPWRD.2009.2030890 